\title{
Resectable Pleural Malignant Mesothelioma
}

National Cancer Institute

\section{Source}

National Cancer Institute. Resectable Pleural Malignant Mesothelioma. NCI Thesaurus.

Code C154441.

Malignant mesothelioma of the pleura that is amenable to surgical resection. 